\title{
JOSÉ ROCABADO*
}

\section{El escenario internacional en los noventa: algunas reflexiones}

\begin{abstract}
Cuál es el futuro del sistema internacional después del "fin de - Cla guerra fría" entre los bloques europeos y el derrumbre de los países socialistas de Europa del Este?, isignifica el aparente "triunfo" del liberalismo económico y político, frente al modelo comunista, el agotamiento del conflicto internacional?, y ¿cual será el papel de las grandes potencias y de otros actores internacionales en el actual sistema internacional? Éstas son algunas de las muchas interrogantes que en los fultimos meses han causado polémica entre analistas y observadores del mundo occidental que se han dedicado a especificar ("pronosticar") los posibles escenarios internacionales. Dar respuesta a esas interrogantes es muy complicado, debido a que el actual contexto internacional es de transición. En todo caso, puede ser más pertinente el detectar algunos rasgos o tendencias del sistema internacional contemporáneo y, sobre esa base, establecer probables escenarios de dicha transición. El proposito de este ensayo es describir dichos rasgos y tendencias y conjeturar acerca de las "reglas" de participación en el sistema internacional de los noventa.

Al principiar la última década del siglo XX, el sistema internacional comprende, simultáneamente, el bipolarismo estratégico, el multipolarismo económico, la interdependencia compleja multinacional y la crisis del desarrollo en el Tercer Mundo. Este tramado internacional se orienta cada vez más hacia la regionalización mundial, es decir, hacia la consolidación de intereses regionales pero dentro de un marco de orden global logrado por Estados Unidos.

Egresado de la Maestría en Economía y Política Internacional, Centro de Investigación y Docencia Económicas (CIDE), México, D.F.
\end{abstract}


Sin embargo, no sólo se está produciendo una "regionalización del mundo", sino también que se está profundizandola separación entre el Norte y el Sur, con el agravamiento de la vulnerabilidad de los países subdesarrollados o periféricos a los principales polos o centros de crecimiento económico y desarrollo tecnológico. Más en específico, cuatro factores caracterizan la compleja estructura y el proceso económico y político del sistema internacional de los noventa. 1

En primer término, la crisis del comunismo (o socialismo real) en la Unión Soviética y la desintegración de este modelo en los países de Europa del Este. En la Unión Soviética esa situación ha conducido, ya desde 1986, a la reestructuración económica y administrativa (perestroika) y la transparencia política (glasnost), además del "nuevo pensamiento político" en las cuestiones mundiales. En los países de Europa del Este, la desintegración del modelo comunista durante 1989 ha derivado en la reforma de sus sistemas políticos mediante la introducción del pluripartidismo y el sistema electoral, como también en la instauración del libre mercado en sus sistemas económicos, aunque la magnitud y profundidad varía de acuerdo a las regiones o sectores económicos de dichas naciones. ${ }^{2}$ (En China, no más de la quinta parte de su sistema económico es de libre mercado y su sistema político -después de Tiananmen- sigue monopolizado por el Partido Comunista.) La tendencia que surge de este contexto es el retraimiento relativo de la Unión Soviética de los asuntos mundiales y la creciente integración de Europa del Este a la dinámina capitalista de Occidente.

En segundo lugar, la competencia (y conflicto) entre Estados Unidos, Alemania Federal y Japón tiende a incrementarse, no sólo por el deterioro de la hegemonía global de Estados Unidos, sino también por el afán de estas potencias por conservar la supremacía en "ausencia" de un liderazgo hegemónico mundial. A ello se añade el debilitamiento de la lucha ideológica entre el comunismo y el liberalismo y, en consecuencia, la primacía de los asuntos económi-

\footnotetext{
${ }^{1}$ James Petras, "Transformaciones glọbales y el futuro del socialismo en América Latina", El Gallo Ilustrado, No. 1456, 20 de mayo de 1990, pp. 2-3, (Suplemento dominical de El Día).

${ }_{2}^{2}$ Irving Howe, "A New Political Situation. Revolutionary Changes in the World", Dissent, invierno de 1990, pp. 87-89.
} 
cos y tecnológicos por encima de los recursos ideológicos y militares. La orientación que sugiere la situación actual de las grandes potencias del Norte es, a partir de una "especialización" en sus respectivas regiones, hacia una marcada competencia (y conflicto) entre esos liderazgos regionales por la supremacía global.

Tercero, Estados Unidos se enfrenta a una paradoja que consiste en la creciente debilidad de su poder económico y financiero y su poderosa influencia ideológica y cultural. La consecuencia de esta realidad ha sido dual. Por un lado, el gobierno norteamericano privilegia la concertación y coordinación de políticas macroeconómicas con las principales potencias del capitalismo desarrollado y se limita al logro de acuerdos-los regímenes internacionales de, por ejemplo, comercio, finanzas y medio ambiente- que mantengan la estabilidad del orden mundial. Por el otro, Estados Unidos enfatiza la destrucción de regímenes políticos y movimientos sociales rivales o enemigos en el Tercer Mundo, es decir, provoca un realineamiento político apoyado por medios modernos de propaganda y publicidad ideológica-cultual, pero sin la capacidad de sostener y promover alternativas viables. El ejemplo más notable de esto último es, sin duda, el caso de Panamá después de la intervención. La tendencia que sugiere esta situación es la creciente asimetría entre el poder "material" y el poder ideológico-cultural de Estados Unidos, que para fines prácticos significa su limitada capacidad de gasto en el sostenimiento de regímenes clientes.

Por último, el relativo retraimiento soviético en los asuntos mundiales (en particular en el Tercer Mundo) y la orientación pro-occidental de los países de Europa del Este, junto al "fin de la guerra fría" entre las alianzas de bloques en Europa, estimulan la expansión "euro-norteamericana" sobre Europa del Este y el Tercer Mundo. Esta expansión puede provocar conflictos nacionales y/o regionales en la periferia mundial, que ya no perarían en el viejo esquema del conflicto Este-Oeste, sino en una renovada lógica de tensión Norte-Sur. Por otra parte, pese a que los acuerdos de desarme estratégico entre la Unión Soviética y Estados Unidos redunden de manera notable en la probabilidad de la escalada nuclear global, con la reunificación alemana el equilibrio europeo ingresa en una etapa incierta, ya que se pone en discusión (como ocurrió en la última cumbre Estados Unidos-Unión Soviética de junio de este año) el 
asunto de las alianzas militares y, con ello, la presión de Estados Unidos y la OTAN para que la Alemania reunificada permanezca en esta alianza. Este asunto es muy problemático como tendencia en tanto una modificación del mapa geoestratégico del continente europeo tiene profundas implicaciones para el equilibrio mundial y, en concreto, para la seguridad de la Unión Soviética, país que aparentemente se opone a la modificación de las fronteras y el equilibrio geoestratégico y militar de Europa.

\section{II}

Los rasgos y tendencias globales mencionados, que son las características más importantes del sistema internacional al principiar la década de los noventa, más que garantizar el fin del conflicto internacional, parecen anunciar una nueva ronda de conflictos económicos y políticos, étnico-raciales y de clase, en los niveles nacionales y regionales.

El repliegue internacional de la Unión Sovietica y el derrumbe de los regímenes de socialismo real en Europa del Este han activado la competencia entre las potencia de Occidente (incluido Japón) ante el "vacio" dejado por la Unión Soviética, tanto en Europa Oriental como en el Tercer Mundo. Si bien la cuestión de estrategia nuclear es arena reservada a Estados Unidos y la Unión Soviética, nada asegura que los asuntos económicos, tecnológicos, comerciales ode inversión, respondan a esa distribución, ya que en la actualidad existen tres grandes bloques regionales en competencia a nivel mundial, liderados cada uno por Alemania reunificada, Japon y Estados Unidos."

Aunque el escenario internacional se ha "derechizado", como lo evidencia el surgimiento de políticas y actores neoliberales en los países de Europa del Este ( $y$ el mantenimiento de éstos en otras partes del mundo), el "triunfo" del modelo liberal en lo económico

\footnotetext{
${ }^{3}$ Noam Chomsky, "El comienzo de la historia" El Gallo Ilustrado, No. 1453, 29 de abril de 1990, p. 11, (Suplemento dominical de EI DGa).
} 
-el libre mercado-y en lo político-el gobierno democrático liberal como forma de organización sociopolítica- no resuelve la multiplicidad de problemáticas mundiales, como tampoco alivia la rivalidad por la supremacía global. En todo caso, estaríamos asistiendo a la búsqueda de soluciones parciales y segmentadas de los problemas de las sociedades y los gobiernos del mundo desarrollado en el marco de una disputa institucional entre liberales "moderados" (o neoliberales) y la socialdemocracia. ${ }^{4}$

A lo anterior se añade la consolidación del "pensamiento neolibe$\mathrm{ral}^{\prime \prime}$ en el resto del mundo, caracterizado por el retraimiento de las funciones económicas estatales en favor del establecimiento de un mercado mundial capitalista donde predominan la formulación macroeconómica gubernamental que favorece a las empresas transnacionales, los principios individuales de competencia y un ejercicio político democrático formal donde la participación ciudadana se limita al proceso electoral.

En esta "nueva" modalidad de dominación, el dominio de la élite tecnoburocrática se "autonomiza" de las voluntades populares y la legitimidad de las funciones gubernamentales se resguarda en la satisfacción de las demandas de consumo "moderno". El mercado pasaría a mediar la relación entre gobernantes y gobernados y la eficiencia del gobierno estaría resguardada por las "leyes del mercado". 5

El escenario internacional de los noventa será probablemente de gran competencia entre sus principales actores. Esta competencia se podría hacer más compleja en la medida en que se siga erosionando la hegemonía estadunidense y se fortalezca el poderío de Europa Occidental y Japón. El caso de la invasión norteamericana a Panamá puede ilustrar este punto. Aunque durante y después de esta intervención se observó un alineamiento occidental, es decir, una política de bloque occidental que respaldó la acción hegemónica de fuerza, los diseñadores de política global de Europa occidental y de Japón han "previsto" que un continuo "despilfarro" de recursos estadunidenses y atención política a espacios marginales (sobre

\footnotetext{
${ }^{4}$ Ricardo de la Peña, "La nueva revolución europea", Política, No. 44, 8 de marzo de 1990, p. 18, (Suplemento semanal de El Nacional); Ludolfo Paramio, "El fin de la prehistoria", Polltica, No. 36, 11 de enero de 1990, p. 11.

${ }^{5}$ De la Peña, op. cit.
} 
todo en el Tercer Mundo) les proprociona más oportunidades económicas y menos competencia para capturar mercados y posibilidades de inversión en Europa del Este, la Unión Soviética y China.

Estados Unidos no sólo carece de una genuina política global para hacer frente a su irreversible erosión de poder, en particular frente a las grandes potencias, sino que cada vez debe endeudarse más con el exterior para financiar sus déficits fiscal y comercial. ${ }^{6}$ Si en 1980 la diferencia entre el monto de las inversiones extranjeras en Estados Unidos y las inversiones norteamericanas en el extranjero arrojó un saldo de 106,000 millones de dólares en favor de éste, para 1989 ese saldo se revirtió a 502,000 millones de dólares en favor de los inversionistas extranjeros en ese país. ${ }^{7} \mathrm{Y}$ sin embargo, pese a que ya no es la superpotencia por excelencia, todavía conserva la capacidad de movilizar a los principales actores internacionales para preservar el orden y la estabilidad mundial. ${ }^{8}$

La nación norteamericana se encuentra en transición de potencia hegemónica a "potencia depredadora", esto es, debe "arrancar ventajas unilaterales para detener su pérdida relativa de poder". ${ }^{9}$ Esta situación le ha conducido a reemplazar el "bilateralismo mundial" por el "bilateralismo selectivo", que se basa en dos principios. Primero, para frenar el deterioro de su posición internacional, Estados Unidos busca "acuerdos de asociación" con otras potencias, pero éstos influyen más en las normas de los regímenes internacionales que sobre la repartición de influencia en un espacio determinado. Por ello, en el caso del continente asiático, puede contar -en diferentes asuntos- con cinco "socios" que, si bien no le son enemigos, tampocole son por completo incondicionales: Japón, Corea del Sur, India, China y la Unión Soviética. El segundo principio consiste en que la selección de sus aliados en el Tercer Mundo se realizará en función a que éstos puedan contribuir en el freno de su deterioro hegemónico. Así, estas naciones deben contar con las siguientes

\footnotetext{
${ }^{6}$ James Petras, "Aislacionismo soviético y expansión euroamericana: de Panamá a Polonia", El Gallo Ilustrado, No. 1448, 25 de marzo de 1990, p. 3, (Suplemento dominical de El Día).

${ }^{7}$ Zaki Laidi, "Las nuevas reglas del juego internacional, Estados Unidos y el bilateralismo selectivo", Cuadernos de Nexos, No. 21, marzo de 1990, p. 6.

${ }^{8}$ Este sería el caso, por ejemplo, de la situación provocada por la invasión de Irak a Kuwait y su posterior anexión.

${ }^{9}$ Laidi, op. cit, p. 6.
} 
características: excedentes financieros susceptibles de ser transferidos a la economía norteamericana, que contribuyan al sostenimiento del gasto militar para la seguridad regional; un mercado abierto lo suficientemente amplio para absorber las exportaciones estadunidenses sin problemas de proteccionismo; y una legitimidad politica y militar que garantice la estabilidad regional o subregional. Dadas las frágiles bases de la hegemonía norteamericana, el bilateralismo selectivo implica la elección limitada de aliados, al tiempo que representa la modalidad más reciente del dominio internacional. $^{10}$

\section{III}

Aun cuando el modelo liberal no se ha extendido sobre el conjunto de las naciones del mundo, el derrumbe del bloque de países de Europa del Este y el repliegue internacional de la Unión Soviética, han sido interpretados por el bloque occidental -en especial por Estados Unidos- como el triunfo definitivo e irreversible de la tradición y el modelo liberal sobre el comunismo (y el socialismo) a nivel global. ${ }^{11}$ Sin embargo, pese a que en la actualidad el escenario internacional se ha "derechizado", hay que hacer notar algunos de los límites para esta "avalancha" liberal.

En primer lugar, es el Tercer Mundo en su conjunto el espacio en donde no se han resuelto los problemas más esenciales del desarrollo y más bien se han agravado a raíz de las llamadas políticas de modernización. En esencia, estas políticas se orientan a la consolidación de sectores económicos destinados a la exportación competitiva que, entre otras cosas, tienen como consecuencia incrementos del desempleo y la pobreza. A esto se agrega el ensanchamiento de la vulnerabilidad de las naciones que componen la periferia global, debido a la brecha que está produciendo, por ejemplo, la sustitución

10 Laidi, op. cit, pp. 7-8.

11 Para un ejemplo de esta "lectura" véase: Francis Fukuyama, "iEl fin de la historia?", El Gallo Ilustrado, No. 1453, 29 de abril de 1990, pp. 2-3, (Suplemento dominical de El Día). 
de las materias primas tradicionales por los nuevos materiales o la "fuga" de recursos financieros para el servicio de la deuda externa.

En el Tercer Mundo, en segundo lugar, están surgiendo nuevos movimientos sociales populares separados del Estado, su aparato burocrático y su ideología autoritaria. ${ }^{12}$ Estos movimientos de la sociedad civil plantean amplias y nuevas demandas a los Estados tecnoburocráticos, en particular por una mejor distribución de la riqueza social, situación que conduce a la prueba de la capacidad de gobernabilidad y legitimidad de la élite gobernante. El dilema presente es cómo satisfacer la multiplicidad de demandas cuando la realidad de la capacidad estatal es su limitada disponibilidad de gasto social. La creciente ola de privatización de las empresas públicas es una respuesta gubernamental transitoria.

En tercer término, la tendencia hacia la "neomercantilización"13 de las relaciones internacionales, y en concreto la regionalización de la economía mundial, está profundizando la marginalización del Tercer Mundo en los asuntos mundiales. En este caso conviene preguntar qué le depara la década de los noventa a América Latina y el Caribe frente a Estados Unidos.

La reciente invasión norteamericana a Panamá, de nueva cuenta, proporciona algunas pistas para esta reflexión. Por un lado, la llamada "década perdida" (la de los ochenta) ha mostrado la crisis y agotamiento del modelo de desarrollo latinoamericano, evidenciado por las abrumadoras deudâs externas nacionales, las altas tasas de inflación (hiperinflación), el estancamiento económico generalizado y el deterioro social, entre otros indicadores. ${ }^{14}$ Por otro lado, el "fin de la guerra fría" no altera el balance de poder en que históricamente se han desenvuelto las relaciones interamericanas. 15 Y sin embargo, Estados Unidos es una "potencia depredadora". Por ello, es plausible sospechar que el gobierno norteamericano, al

${ }^{12}$ Alain Touraine, "Seguir siendo socialistas", El Gallo Ilustrado, No. 1453, 29 de abril de 1990, p. 13.

${ }_{13}$ André Gunder Frank, "El ajuero negro de la deuda", El Gallo Ilustrado, No. 1450,8 de abril de 1990, p. 6.

${ }^{14}$ Abraham Lowenthal, "América Latina en los noventa", Cuadernas de Nexas, No. 20, febrero de 1990, pp. 10-11.

is Arturo Borja, "Panamá y las relaciones hemisféricas", Cuadernas de Nexas, No. 20 , febrero de 1990 , p. 3. 
tiempo de no promover alternativas creibles de desarrollo, no deja de considerar la invasión militar en aquellas naciones que percibe como una amenaza a su seguridad nacional. Si a esto se le agrega la creciente militarización de la "guerra contra las drogas", se puede imaginar a la región andina como un escenario muy problemático. 